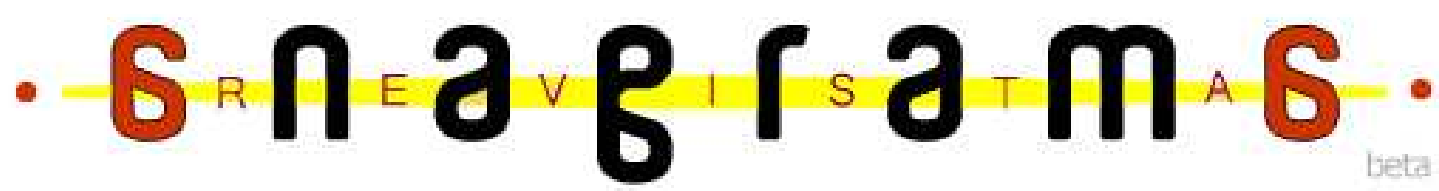

\section{Internet e Participação: uma análise do Portal Gabinete Digital}

Anna Cristina Brisola ${ }^{7}$

Taís Leaf

Evellyn Pacheco ${ }^{3}$

Fabiana Crispino"

\section{Resumo}

O presente artigo tem por objetivo analisar a questão da mobilização social na internet a partir da iniciativa estatal, especialmente o que se refere ao estímulo à participação e à interação. Para isso foi escolhido como estudo de caso a votação promovida pela ferramenta Governador Pergunta, do portal Gabinete Digital, idealizado pelo governo do Estado do Rio Grande do Sul.

Palauras-chaue: Mobilização; Internet; Governador Pergunta.

\section{Introdução}

Segundo o modelo de Rousseau ${ }^{5}$, a cidadania é um direito coletivo que favorece a individualidade, pressupõe a ação política e implica a aquisição de direitos e o cumprimento de deveres pela sociedade. Além disso, "as liberdades têm de ser exercidas e não só garantidas" (ELSTER apud CABRAL, 2003:32), o que significa que o exercício da cidadania só ocorre a partir de processos de educação, aprendizagem, informação e conscientização do cidadão.

1 Estudante de Graduação $7^{\circ}$ período do Curso de Jornalismo da UNISUAM, email: anna.brisola.jor@hotmail.com.

2 Estudante de Graduação $6^{\circ}$ período do Curso de Publicidade da UNISUAM, email: tais.n.leal@ gmail.com.

3 Estudante de Graduação $7^{\circ}$ período do Curso de Jornalismo da UNISUAM, email: evellyn.pacheco@hotmail.com.

4 Orientadora do trabalho. Professora do Curso de Comunicação da UNISUAM, email: fabi_crispino@yahoo.com.

5 Ver

BATISTA,

2005.

Disponível

em

<http://www2.metodista.br/unesco/agora/mapa_animadores_pesquisadores roseli.pdf>. Acesso em $21 / 03 / 2012$. 
Esses elementos são importantes para que o indivíduo tome conhecimento do ambiente social, político e econômico onde se encontra e, assim, tenha a capacidade de desenvolver senso crítico para exercer seus direitos e deveres. Por exemplo, para que o cidadão pratique seu direito ao voto é necessário, teoricamente, que ele tenha um prévio entendimento de questões políticas para escolha do melhor representante.

O estudo de Manuel Cabral indica que o pleno exercício da cidadania - que de acordo com o autor vai além da participação eleitoral - está intimamente ligado à informação e à educação, "sendo as pessoas mais instruídas e mais jovens as que revelam maior tendência para se mobilizarem" (2003:36).

No que se refere ao conceito de mobilização, Toro (1996:5) explica que "mobilizar é convocar vontades para atuar na busca de um propósito comum, sob uma interpretação e um sentido também compartilhados”. A mobilização vai além da aglomeração, e está diretamente ligada à escolha e à afinidade de ideais e motivações.

À capacidade de promover em si mesmo esta mobilização, que busca a cidadania e a participação social, Cabral chama de automobilização, que por sua vez está atrelada ao valor que o indivíduo atribui a sua própria opinião, à maneira de absorver a informação, ao acesso à mídia informativa e ao capital escolar. Essa capacidade e consciência impulsionam a participação social e o exercício da cidadania:

A automobilização está também correlacionada, embora mais mitigadamente, com a mobilização cognitiva e a exposição à mídia informativa, que assim continuam a andar a par. Em contrapartida, a classe social e o rendimento possuem fracas correlações, mostrando a mobilização depender mais diretamente do "capital escolar" do que do "capital econômico" ou do chamado habitus de classe (CABRAL, 2003:36).

Nesse sentido, a vontade de automobilizar depende muito mais de questões educacionais do que do poder aquisitivo do indivíduo. A educação, neste caso, está sujeita à exposição do individuo às mídias e aos contextos que lhe forneçam o devido conhecimento, que lhe sirvam de ponte para o seu exercício da cidadania.

$\mathrm{O}$ advento da web 2.0 deu subsídios para que diferentes organizações da sociedade civil se comunicassem de forma mais ágil, compartilhando informações, conteúdo e ideias, o que, em tese, tornaria mais fácil o estímulo e a prática da mobilização e da automobilização. Essa facilidade é possível graças às características naturais da rede, como o incremento da interação, da participação e da sua qualidade anárquica, ou seja, a 
ausência de hierarquia, controle e de um ponto fixo e central de partida das informações.

Como exemplo de interação e participação da sociedade civil no início da web 2.0, pode ser citado o caso do conglomerado japonês Bridgestone-Firestone, ocorrido em julho de 1996. Nesta ocasião, 2.300 grevistas seriam substituídos nas usinas da empresa, nos Estados Unidos, por trabalhadores avulsos.

Para reverter o quadro e mobilizar a sociedade contra a decisão, foram disponibilizados no site da Federação Internacional dos Sindicatos de Trabalhadores em Indústrias Químicas (Icem) um abaixo assinado virtual, o qual qualquer pessoa podia assinar e remeter aos destinatários escolhidos e catalogados previamente pela Icem.

Dentre os endereços eletrônicos constantes na lista estavam os de autoridades governamentais, formadores de opinião, mídias do mundo inteiro, diretores da matriz e das filiais do grupo Bridgestone, entre outros. Em poucos minutos, todas as caixas postais escolhidas estavam lotadas de e-mails e a repercussão do caso apareceu em diversos telejornais, na Europa e no Japão, que noticiaram o fato com destaque fazendo com que a empresa viesse a público para explicar e rever a sua decisão contra os trabalhadores (MORAES, 2000:148).

Com essa nova possibilidade de fluxo multidirecional de comunicação, no qual inúmeras fontes podem iniciar o processo comunicativo (SOUSA; MEDEIROS, 2010:8), muitos movimentos sociais migraram para a rede com o intuito de utilizá-la como aliada, uma vez que ela se mostrou uma alternativa à unidirecionalidade dos meios de comunicação tradicionais e uma forma de trazer ao conhecimento da sociedade as principais reivindicações e problemas sociais, políticos e econômicos enfrentados no mundo de hoje.

De acordo com Pierre Lévy (1998:44), pode-se dividir o processo comunicativo em três esquemas: "um para todos", "um para um" e "todos para todos". No primeiro esquema, "um centro emissor envia mensagens na direção de receptores passivos e, sobretudo, isolados um dos outros", como no exemplo da televisão. Na comunicação "um para um" o esquema é feito ponto a ponto, como o que ocorre com o telefone, pois a mensagem é enviada com precisão e diretamente ao seu receptor, e permite reciprocidade dele.

Já a internet, para o autor (1998:44), “combina as vantagens dos dois sistemas anteriores. De fato, permite, ao mesmo tempo, a reciprocidade na comunicação e a partilha de um contexto", concretizando o sistema "todos para todos". 
O ambiente digital permitiu e potencializou alternativas para a mobilização e a organização da sociedade civil, através de uma nova ótica, espaço e formato. A internet permite a interação de múltiplos agentes, transcendendo as fronteiras geográficas, e assim possibilitando o engajamento em discussões que ocorrem nas redes sociais, nos fóruns de debates, nos chats, nos espaços virtuais, e que estimulam a participação social e a cidadania (RHEINGOLD; DAHLBERG apud MAIA, 2007:48).

É o que acontece, por exemplo, com os sites produzidos por moradores de favelas ${ }^{6}$, através dos quais a cultura, as raízes, a divulgação de eventos culturais ou de notícias passam simbolicamente a construir uma identidade local, o que pode fortalecer um discurso próprio (MAIA, 2007:50).

Não só a sociedade civil pode se apropriar e beneficiar das características da rede para manifestar suas vontades, desejos e reivindicações, como também o Estado, que encontra nesse ambiente, formas de se fazer presente junto à sociedade civil, seja ouvindo, debatendo, ou apenas disponibilizando um espaço para exposição das contestações, entre outras possibilidades.

$\mathrm{Na}$ medida em que os cidadãos usam as ferramentas digitais como forma de disseminar suas ideias e trocar experiências - aproveitando-se do discurso de participação e interação da rede - a presença do Estado neste ambiente pode possibilitar uma proximidade na relação entre as instituições governamentais e a sociedade, fazendo com que tal aproximação seja desdobrada para além do voto, ou seja, da escolha de um representante político:

Para além da participação direta em instâncias formais do Estado, um crescente número de autores vem ressaltando a importância da educação cívica e política dos cidadãos, o cultivo do senso de comunidade, bem como as dinâmicas de conversação e de deliberação, a fim de assegurar que as preferências acerca de representantes ou de políticas públicas sejam bem informadas e que ações diversas, por parte dos cidadãos, possam subsidiar e controlar democraticamente a agenda e a produção da decisão política (MAIA, 2007:44).

No Brasil, o panorama descrito por Maia tem sido desenvolvido na forma de iniciativas relacionadas a uma utilização estatal das ferramentas digitais. Cada vez mais representantes e órgãos do Governo disponibilizam recursos digitais através dos quais é

6 Como exemplos, as iniciativas do Observatório de Favelas (<http://www.observatoriodefavelas.org.br〉) e da Central Única das favelas (<http://www.cufa.org.br >). 
possível que o cidadão tenha acesso às informações sobre as principais ações governamentais, as leis votadas, os serviços prestados pelo Estado e outras informações sobre a administração pública. No site do Tribunal de Contas da União (TCU) ${ }^{7}$, por exemplo, o indivíduo que tiver interesse pode ter acesso ao relatório de prestação de contas de cada ano.

Além de portais de caráter informativo, existem também algumas iniciativas do Estado, no âmbito da web 2.0, que têm o objetivo de mobilizar os cidadãos e incentivar sua participação na gestão de questões governamentais.

Nesse sentido, o presente artigo tem como objetivo analisar determinados aspectos da relação entre a mobilização social e a internet, especialmente o que se refere à apropriação estatal desse processo. Diversos autores (MORAES, 2000; MEDEIROS, 2011) abordam esta questão partindo do ponto de vista das diferentes associações da sociedade civil e como elas utilizam a internet como ferramenta para expor e debater problemas da sociedade, sejam eles de ordem política, social ou econômica.

Para abordar a mobilização na internet como base organizacional e iniciativa especificamente do Estado, foi selecionado como objeto de estudo o portal Gabinete Digital $^{8}$. O portal foi idealizado pelo Governo do Estado do Rio Grande do Sul e tem como objetivo estimular a mobilização na sociedade civil, através da abordagem de problemas e da busca de alternativas junto à própria sociedade.

Como metodologia, foi realizado um estudo de caso de uma das ferramentas do Gabinete Digital, o Governador Pergunta. Em uma primeira fase, foi efetuado um levantamento bibliográfico e, em seguida, foram analisados os dados disponíveis no portal sobre a última edição realizada do Governador Pergunta a fim de discutir o potencial de mobilização despertado.

\section{0 portal Gabinete Digital}

O portal Gabinete Digital foi desenvolvido pelo Estado do Rio Grande do Sul e lançado em maio de 2011. O projeto foi pensado a partir da proposta de criação de uma ferramenta de contato direto com o governador, Tarso Genro, com o propósito de incentivar a participação da população nas decisões políticas, como forma de fortalecimento da democracia.

7 Disponível em: < http://portal2.tcu.gov.br/TCU>. Acesso em: 01/04/2012.

8 Disponível em: <http://www.gabinetedigital.rs.gov.br/>. Acesso: 20/04/2012. 
A ideia divulgada era a de promover um espaço digital no qual o cidadão pudesse participar da gestão governamental, através de ferramentas que lhe permitissem o acesso a mesas redondas virtuais, canais para registro de reclamação e sugestões ao governo. $\mathrm{O}$ intuito era estimular um processo de fortalecimento da democracia, no qual a "mobilização em rede seja, não um suporte, mas um dos eixos estruturais da democracia" (apud AMORIM, 20119).

De acordo com o tutorial do próprio portal, desde sua implantação foram feitas modificações para se adequar aos avanços do mundo digital e para facilitar o acesso pela população. O Gabinete Digital funciona atualmente através de quatro ferramentas principais:

- Agenda Colaborativa: um espaço onde a população de qualquer região do Estado, inclusive os habitantes das cidades do interior, possa participar do gabinete virtual. O internauta interage com a agenda do Governador sugerindo pautas, que poderão ser desenvolvidas durante as visitas que ele e seus Secretários fazem ao decorrer do ano pelo interior. Ou seja, a proposta da agenda colaborativa é diminuir a distância entre o Estado e os cidadãos, principalmente das regiões interioranas da capital, facilitando o conhecimento das demandas da população.

- Governo Escuta: através desta ferramenta abre-se um espaço de discussão no qual a população tem a oportunidade de participar de audiências públicas, que são transmitidas ao vivo, via internet, enviando suas contribuições através de bate-papo e das redes sociais.

Em entrevista, o coordenador da Assessoria Superior do Governador, secretário Flávio Koutzii, declarou ao Agora O Jornal do Sul, que a meta desta ferramenta é "propiciar, através de múltiplas relações entre o governo e a sociedade, um canal de discussão aberto sobre projetos ou temas importantes"10.

As audiências geralmente acontecem com data marcada, assunto determinado e em locais específicos, e as participações dos internautas são respondidas durante o próprio fórum.

Tarso Genro, respondendo a uma das internautas", afirmou que "por meio deste fórum, o Executivo serve-se do conhecimento, que é produzido fora do Governo, para aprender”. Isto é, a participação, mesmo que limitada, dos cidadãos, possibilitaria aos

9 Disponível em: <http://www.jornalagora.com.br/site/content/noticias/detalhe.php?e=3\&n=11455/>. Acesso em: 24/04/2012.

${ }^{10}$ Idem.

11 No dia 04 de maio de 2011, durante o Primeiro Fórum O Governo Escuta, no Palácio Piratini, em Porto Alegre, com o tema Violência no Ambiente Escolar, Bullying e seus Desdobramentos. Disponível em: <http://www.seduc.rs.gov.br/pse/html/noticias_det.jsp?PAG=166\&ID=6385>. Acesso em: 24/04/2012. 
membros do governo o acesso à opinião pública, estimulando a mobilização e a politização.

- Governador Responde: os internautas podem enviar suas perguntas livremente ao portal, e "todas as perguntas serão aprovadas, desde que estejam de acordo com a Política de Contribuição o os Termos de Uso do site" ${ }^{\text {"12 }}$. As perguntas são então submetidas à votação virtual, que pode ser estimulada pelo próprio autor através de divulgação de sua pergunta pelas redes sociais e $e$-mails, pedindo votos. A pergunta mais votada do mês é então respondida pelo Governador em vídeo, que fica disponível no portal.

Essa interação provoca não só o interesse dos autores das perguntas como também dos votantes, havendo assim um aumento da procura pela resposta dada pelo Governador. Há ainda o estímulo colateral criado pelos autores, quando divulgam suas perguntas, para o portal e a possibilidade de voto para a população em geral. O Governador pode ainda escolher responder também, a qualquer tempo, uma pergunta que não necessariamente foi a mais votada.

- Governador Pergunta: esta ferramenta será analisada com mais ênfase a seguir, mas consiste, basicamente, na publicação de uma questão que é levantada pelo Governador. Depois disso, a sociedade é convidada a responder à questão enviando propostas de melhoria. Ao final, os autores das propostas mais votadas participam de um encontro com o Governador.

\section{A ferramenta Governador Pergunta}

O funcionamento da ferramenta Governador Pergunta parte da publicação de uma questão levantada pelo governo. A população é estimulada a enviar propostas para solucionar a questão levantada e tais propostas são votadas pelos próprios internautas, de qualquer parte do país, sem necessidade de identificação. As melhores contribuições participam de um encontro com o Governador.

A primeira edição do Governador Pergunta teve início no dia 9 de novembro de 2011 e foi dividida em quatro etapas. A primeira etapa teve início no próprio dia 9, quando a ferramenta foi apresentada no portal e a seguinte questão levantada: "Como podemos melhorar o atendimento na saúde pública?".

Ao final do dia, teve início a segunda etapa da ferramenta, que durou até o dia 28 de novembro de 2011. Dentro deste prazo, os internautas poderiam enviar propostas sobre a saúde pública. Para o envio das propostas, era necessário que o cidadão acessasse o Gabinete Digital, fizesse seu cadastro e escolhesse a ferramenta Governador Pergunta,

12 Disponível em: <http://www.gabinetedigital.rs.gov.br/>. Acesso em: 24/04/2012. 
que oferecia um passo a passo explicativo de funcionamento e, ainda, uma divisão em cinco temas sobre saúde pública - Cuidado Integral, Medicamentos, Saúde da Família, Saúde na sua Região e Urgência e Emergência. Finalmente, o cidadão teria de escolher entre os cincos temas qual se adequaria melhor à sua proposta e, assim, enviá-la pelo portal.

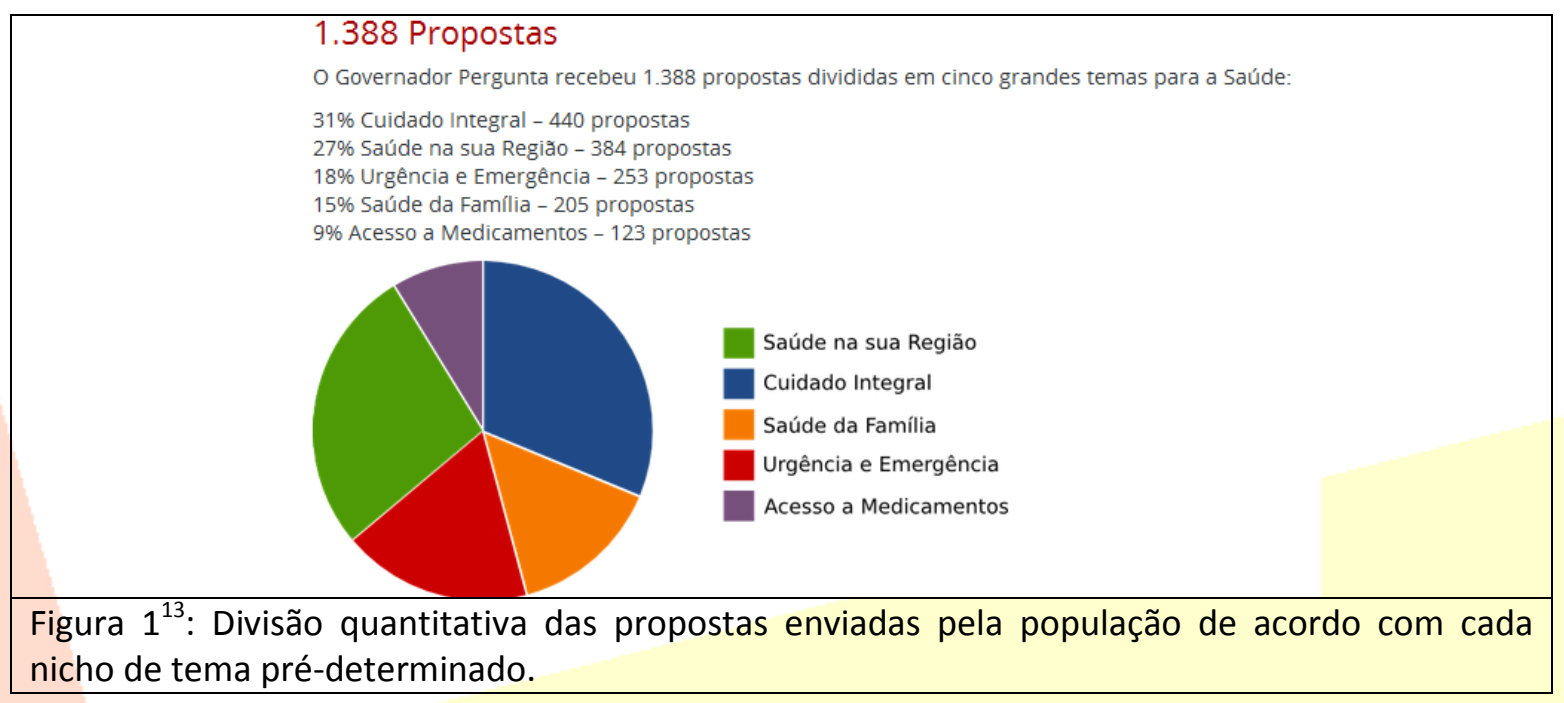

Em 30 dias de consultas, foram enviadas 1.388 propostas, disponibilizadas ao voto no portal. Após 122.609 votos e o envolvimento de 60 mil pessoas, 50 propostas foram priorizadas. No dia 14 de dezembro de 2011 o governador recebeu os autores das propostas vencedoras no Palácio do Piratini. Os resultados foram divulgados no dia 17 de dezembro em Tramandaí ${ }^{14}$.

Além do voto, a acessibilidade foi levada em consideração: a Van da Participação percorreu diversos pontos de Porto Alegre e da Região Metropolitana, disponibilizando computadores e acesso ao Governador Pergunta, possibilitando que mais de 10 mil cidadãos participassem da etapa inicial, sendo 7,5 mil somente no interior. Também foram instalados computadores em oito espaços públicos da capital e sete telecentros no interior do Estado, totalizando 25 mil acessos ao portal durante o período do evento ${ }^{15}$.

\section{Análise}

A partir da explicação da dinâmica da ferramenta Governador Pergunta - que se

13 Disponível em: <http://www.gabinetedigital.rs.gov.br/govpergunta/results/govpergunta/results/p4>. Acesso em: 17/04/2012.

14 Idem.

15 Idem. 
propõe a ser uma "ferramenta inovadora de participação online"16 - é possível fazer uma análise mais aprofundada sobre o seu funcionamento e eficácia partindo do conceito da mobilização social.

Para isso foram selecionados alguns dos dados contidos no site, tais como o número de participantes e de votos e os resultados da primeira edição da ação. Foram comparados também os métodos utilizados para a seleção das perguntas e o método de votação.

O processo de levantamento de votos do Governador Pergunta foi inspirado no método desenvolvido pelo All Our Ideas, grupo de pesquisa norte-americano desenvolvido por alunos da Universidade de Princeton ${ }^{17}$.

Os programas de coleta de dados do All Our Ideas têm como objetivo uma transformação na forma habitual de votação, nos quais os participantes escolhem de forma engessada alguma das opções oferecidas, sem poder interagir com as propostas para votar. Com o modelo criado pelo grupo de pesquisa, além das respostas rápidas, há possibilidade de interação do participante.

A ideia é a combinação de características quantitativas e qualitativas, através do uso da web. Por se tratarem de assuntos que fazem parte do cotidiano dos participantes, a escala de velocidade das pesquisas é alta, e a pretensão é permitir aos envolvidos a discussão e o conhecimento de novas informações.

Além disso, no caso do Governador Pergunta existe a possibilidade de cada concorrente, ou seja, cada cidadão que enviou resposta à questão proposta, de compartilhar entre seus conhecidos e em redes sociais suas respostas e pedir votos. Com isso, mais pessoas entram em contato com a votação e a ferramenta, possibilitando o seu envolvimento no processo.

Conforme comentado anteriormente, a ferramenta não é contínua, ou seja, não está disponível para uso no portal a qualquer momento. Ela é disponibilizada em caráter de sazonalidade, em edições com datas pré-definidas para início e fim. Em se tratando da mobilização e consequente participação da sociedade através desta ferramenta, em específico, já se nota a uma limitação por questões temporais, uma vez que existe um período determinado para envio das sugestões e outro para votação.

Outra questão importante é a necessidade de enquadramento das sugestões enviadas

16 Disponível em <http://www.gabinetedigital.rs.gov.br/govpergunta/results/govpergunta/results/p4>. Acesso em: 24/04/2012.

17 Disponível em: <http://www.allourideas.org/>. Acesso em 29/04/2012. 
dentro de categorias pré-estabelecidas. Apesar da abertura, a princípio, para a participação de qualquer membro da sociedade, as sugestões enviadas deveriam estar enquadradas em perfis previamente estabelecidos pelo programa.

De um lado, é necessário que se tenha um método e um agrupamento de ideias que estabeleçam protocolos a serem seguidos pela lógica digital. Entretanto, ao limitar as categorias de participação, há um cerceamento de possíveis sugestões inovadoras, que poderiam enriquecer o processo.

A população do Estado do Rio Grande do Sul, de acordo com o último Censo Demográfico 2010 do IBGE (Instituto Brasileiro de Geografia e Estatística) ${ }^{18}$, é de 10.393.929 habitantes. Deste total, apenas 1.219.879 domicílios permanentes possuem microcomputadores com acesso à internet, segundo dados do mesmo Censo Demográfico. Baseando-se nestes dados é possível constatar que nem 1/4 da população do Estado possui acesso à internet e, por isso, não está capacitada, do ponto de vista material, para participar de processos de participação política como o proposto pelo Gabinete Digital.

Uma tentativa de trabalhar com este quadro e gerar um estímulo à participação política, foram ações como as Vans da Participação, que eram levadas a locais públicos e a municípios mais afastados da capital, disponibilizando computadores com acesso à internet para os moradores locais.

Além das Vans da Participação, foram disponibilizados em oito espaços da capital computadores com acesso direto ao Governador Pergunta, além de Telecentros no interior do Estado, como nas cidades de Canoa e Cacequi ${ }^{19}$.

Mesmo assim, de acordo com informações contidas no portal do Gabinete Digital, estima-se que cerca de 10 mil pessoas participaram da votação através das "Vans da Participação". Comparando este quantitativo com o total da população (2.786.853 pessoas) dos municípios que as vans visitaram ${ }^{20}$ - Porto Alegre, Sapiranga, Esteio, Sapucaia do Sul, São Leopoldo, Novo Hamburgo, Canoas, Alvorada e Cachoeirinha -, esse número ainda representa uma pequena parcela da população do Estado, não representando uma amostra significativa.

Nessa linha de pensamento, é necessário repensar a questão da participação efetiva

\footnotetext{
${ }^{18}$ Disponível em < http://www.censo2010.ibge.gov.br/amostra/>. Acesso em 29/04/012.

19 As listas dos locais de visitação das "vans da participação" e da localização dos pontos de acesso público na capital e interior do Estado estavam disponíveis no portal (<http://gabinetedigital.rs.gov.br/wp/wpcontent/uploads/2011/12/Mapa-Van-0112.pdf>. Acesso em 29/04/2012).

${ }^{20}$ Ver nota 16.
} 
da população através da internet. De acordo com Gomes (2005:221):

Pesquisas demonstram, ademais, que as discussões políticas online, embora permitam ampla participação, são dominadas por uns poucos, do mesmo modo que as discussões políticas em geral. Em suma, apesar das enormes vantagens aí contidas, a comunicação online não garante instantaneamente uma esfera de discussão pública justa, representativa, relevante, efetiva e igualitária.

A partir da afirmação do autor, é possível ver que a participação política digital ainda se dá de forma a reproduzir a participação política do plano analógico. As características da internet, sua capacidade de interação e participação, já mencionadas neste artigo, apresentam um cenário de possibilidades positivas para a otimização dos processos comunicativos, porém apenas a existência dessas características não configuram plenamente um quadro de igualdade, discussão, justiça e participação.

Para que esse quadro seja, de fato, efetivo do ponto de vista político e democrático, é preciso retomar o pensamento de Cabral (2003:32) de que "as liberdades têm de ser exercidas e não só garantidas", e pensar na questão do exercício da cidadania que parte de processos de educação e conscientização do cidadão.

Percebe-se assim que a participação pública ainda é limitada, e que cabe aos proponentes, neste caso o Governo do Rio Grande do Sul, esforços ainda maiores, para que os excluídos digitalmente, parcela ainda grande da população, tenham mais acesso a estes processos. E para além da simples disponibilização de computadores com acesso à internet, cabe a conscientização da população da importância da participação nas decisões públicas, que só acontece através da educação, da conscientização cidadã e politização da população.

Os esforços do Gabinete Digital para mobilizar o público incluíram ações como a visita da equipe do Gabinete Digital aos servidores do IPE - Instituto de Previdência do Estado do Rio Grande do Sul - com o objetivo de informar a respeito do portal e incentivar o envio de propostas para melhorar o atendimento na saúde. A ferramenta também foi apresentada para membros de sindicatos, federações, organizações relacionadas à saúde e a lideranças étnicas, políticas e religiosas, com o objetivo de difundir a participação online.

Além dos esforços da equipe do portal para promover a ferramenta e fomentar a participação, houve também uma repercussão do Gabinete Digital através dos discursos midiáticos. A imprensa divulgou amplamente no Estado o evento, dando destaque ao lançamento do portal e da primeira edição do Governador Pergunta.

Veículos como O Jornal do Comércio, Revista Fórum, Zero Hora, O Sul, Correio do 
Povo, e meios digitais como Observador Político, Luiz Nassif Online, Rádio Guaíba, Epolitico.net, entre outros, foram responsáveis pela geração de uma quantidade expressiva de mídia espontânea. Foram 109 matérias, em 60 sites ou blogs, 29 jornais, 15 rádios, 5 TVs e 2 revistas, sendo 3 internacionais, 35 nacionais, 21 na capital do Estado e 34 no interior $^{21}$.

Das matérias internacionais, destaca-se a cobertura do blog espanhol 20 minutos.es, em especial o texto Código abierto, de Bernardo Gutierres, no qual o autor afirma entender o Gabinete Digital como um "protótipo tecnopolítico que seria o sonho de movimentos como o El 15M espanhol"22.

Gutierres reconhece no portal a utilização de vários tipos de ferramentas para dialogar com os cidadãos, "tendo [o Gabinete Digital] entendido que abrir perfis em redes sociais não é sinônimo de diálogo"23. Para o autor, a política 2.0 se constrói mais com vontade do que com tecnologia, e iniciativas como o Gabinete Digital funcionam como saltos quânticos da democracia representativa e participativa.

Até a conclusão deste artigo, o trabalho com as propostas ${ }^{24}$ resultantes das votações do Governador Pergunta limitaram-se a uma divulgação no portal do Gabinete Digital, nos meios de comunicação e um evento de apresentação dos autores diante do Governador, seus Secretários e Assistentes, a partir de uma audiência pública presencial e online. A reunião foi veiculada através do portal e manteve-se disponível para visualização posterior.

O governador declarou que algumas propostas já estavam sendo anteriormente discutidas pelo governo, e que as ideias da população vieram ao encontro das vontades públicas. Embora tenha sido acordado que as sugestões geradas pelo projeto ${ }^{25}$ seriam discutidas pelas Secretarias, não existem garantias de que todas as propostas serão aproveitadas ou implementadas na íntegra..

\section{Conclusão}

Apesar das limitações quanto ao acesso, não só da internet, mas da informação e da

21 Disponível em: <http://www.gabinetedigital.rs.gov.br/post/1075>. Acesso em: 18/04/2012.

${ }^{22}$ Disponível em <http://blogs.20minutos.es/codigo-abierto/2012/01/31/el-meneame-de-la-politica/>. Acesso em: 25/04/2012.

23 Idem.

${ }^{24} \mathrm{O}$ relatório com as 50 propostas priorizadas e suas respectivas respostas está disponível em: <http://gabinetedigital.rs.gov.br/wp/wp-content/uploads/2011/12/relatorio-govpergunta-122011.pdf >. Acesso em: 15/05/2012.

${ }^{25}$ Disponível em: <http://www.gabinetedigital.rs.gov.br/videos/14〉. Acesso em: 10/05/2012. 
conscientização para a educação, de modo geral, também é preciso atentar para o fato de que o Gabinete Digital, a partir da sua proposta de inclusão da sociedade em processos de decisão política através de ferramentas virtuais, pode servir como ponto de partida para reflexão da sociedade sobre a importância de intervir e participar de tais processos.

Uma vez que a população, especialmente a parcela que detém o conhecimento político e participa de forma ativa, tem interesse em engajar-se nas políticas de participação online como a ferramenta Governador Pergunta, existe a possibilidade de configuração de um cenário onde, através das características próprias da rede comunicação multidirecional, capacidade interação e participação - os sujeitos possam se comunicar e incentivar pessoas ao seu redor, caracterizando assim uma rede de mobilização online.

Segundo Cabral, apesar dos espaços de mobilização política ainda serem lugares privilegiados, "nada politiza mais que a politização" (2003:36). Mesmo que existam variáveis que dependem dos sistemas de diferenciação social, "tanto a procura de informação como a disposição para intervir no espaço público e discutir assuntos de caráter político constituem, em si próprias, manifestações potenciadoras do exercício da cidadania" (2003:36).

Desta maneira, os movimentos que promovem a discussão política e geram algum tipo de mobilização podem estar cumprindo um papel politizador e, ao atingir outras pessoas, estas ações geram mais mobilização e politização. Partindo do Estado, esses movimentos podem ganhar ainda mais visibilidade.

Sob este aspecto, mesmo que ainda de forma reduzida, iniciativas como o Governador Pergunta geram um movimento de interação e de apropriação da palavra, da sugestão e do voto. Entrando no portal, utilizando suas ferramentas e participando das propostas os cidadãos passam a, de alguma maneira, se apropriar de suas funções de cidadania e participação política.

Um elemento que deve ser ressaltado para melhor compreender a ferramenta é a diferença entre participação e poder de decisão. A ferramenta Governador Pergunta não confere poder de decisão política à população, pois a votação não é feita para escolher qual proposta será, de fato, implementada.

O que existe é uma votação para escolher as melhores propostas com o intuito buscar junto à população possíveis alternativas para problemas atuais, o que aproxima o processo à perspectiva de mobilização apresentada por Toro (1996:5), pois convoca indivíduos a 
participarem de um mecanismo no qual o objetivo comum é a busca por respostas aos problemas da sociedade.

Mas como foi discutido, a prática da cidadania, a mobilização e a automobilização no ambiente digital requerem não só acesso à internet, mas um embasamento político-cultural mais sólido, adquirido, por exemplo, através do acesso à informação e à educação.

Por fim, é possível concluir que a natureza participativa da rede não basta para que de fato se configure a participação e a mobilização. É necessário que os indivíduos estejam capacitados não só materialmente para que usufruam do conhecimento adequado para se tornarem indivíduos ativos politicamente e com capacidade de exercer, plenamente, sua cidadania.

\section{Referências Bibliográficas}

AMORIM, Paulo Henrique. Tarso lança Gabinete Digital. Blog Conversa Fiada. Disponível em: $<$ http://www.jornalagora.com.br/site/content/noticias/detalhe.php?e=3\&n=11455/>. Acesso em: 24/04/2012.

BATISTA, Roseli Araújo. $O$ acesso a informação como requisito para o exercício da cidadania. Disponível em: <http://www2.metodista.br/unesco/agora/mapa_animadores_pesquisadores_roseli. pdf.> Acesso em 21/03/2012.

CABRAL, Manuel Villaverde. O exercício da cidadania política em perspectiva histórica (Portugal e Brasil). Revista Brasileira de Ciências Sociais (RBCS), Vol. 18 nº 51 fevereiro/2003. Disponível em: < http://www.scielo.br/pdf/rbcsoc/v18n51/15985.pdf >. Acesso em 20/03/2012.

CENSO Demográfico 2010 IBGE. Disponível em: <http://www.censo2010.ibge.gov.br/amostra/>. Acesso em: 29/04/2012.

GABINETE Digital. Disponível em: <http://www.gabinetedigital.rs.gov.br/>. Acesso em: $15 / 03 / 2012$

GOMES, Wilson. A democracia digital e o problema da participação civil na decisão política. Revista Fronteiras - Estudos Midiáticos, Vol. VII, n 3, setembro/dezembro de 2005. Disponível em: 
<http://www.unisinos.br/publicacoes_cientificas/images/stories/Publicacoes/fronteirasv9n3/09_art0

7_gomes.pdf>. Acesso em: 29/04/2012.

LÉVY, Pierre. A Revolução contemporânea em matéria de comunicação. Revista Famecos, nº 9 , dezembro de 1998, Porto Alegre. Disponível em: $<$ http://revistaseletronicas.pucrs.br/ojs/index.php/revistafamecos/article/viewFile/3009/2287>.

Acesso em: 20/04/2012.

MAIA, Rousiley, C. M. Redes cívicas e internet: efeitos democráticos do associativismo. LOGOS, $\mathrm{n}^{\circ} \quad 27, \quad$ Ano 14, $2^{\circ}$ semestre de 2007. Disponível em: <http://www.logos.uerj.br/PDFS/27/04_ROUSELY_MAIA.pdf>. Acesso em 19/03/2012.

MEDEIROS, Priscila Muniz de. Ciberespaço, Democracia e Globalização: Uma Análise do Ciberativismo do Avaaz. XXXIV Congresso Brasileiro de Ciências da Comunicação, 2011, Recife. Disponível em: <http://www.intercom.org.br/papers/nacionais/2011/resumos/R6-1413-1.pdf>. Acesso em: 15/03/2012.

MORAES, Denis de. Comunicação virtual e cidadania: movimentos sociais e políticos na Internet. Revista Brasileira de Ciências Sociais (RBCS), Vol. 23, nº 2, julho/dezembro de 2000. Disponível em: <http://www.bocc.ubi.pt/pag/moraes-denis-ativismo-digital.html>. Acesso em 20/03/2012.

SOUSA, Marcelo Igor de; MEDEIROS, Magno Luiz da Silva. Jornalismo Cidadão na Internet: Modelo participativo e suas implicações na comunicação e na sociedade. XII Congresso de Ciências da Comunicação na Região Centro-Oeste, 2010, Goiânia. Disponível em: < http://www.intercom.org.br/papers/regionais/centrooeste2010/resumos/R21-0316-1.pdf>. Acesso em: 20/04/2012.

TORO, Jose Bernardo; WERNECK, Nisia Maria Duarte Furquim. Mobilização social: um modo de construir a democracia e a participação. UNICEF, Brasil, 1996. Disponível em: $<$ http://www.aracati.org.br/portal/pdfs/13_Biblioteca/Publicacoes/mobilizacao_social.pdf $>$. Acesso em 19/03/2012. 